\title{
Two-dimensional finite elements model for selenium transport in saturated and unsaturated zones
}

\author{
Gokmen Tayfur • Kenneth K. Tanji • Alper Baba
}

Received: 12 March 2009 / Accepted: 9 October 2009 / Published online: 28 October 2009

(C) Springer Science + Business Media B.V. 2009

\begin{abstract}
A two-dimensional finite element model was developed to simulate species of selenium transport in two dimensions in both saturated and unsaturated soil zones. The model considers water, selenate, selenite, and selenomethionine uptake by plants. It also considers adsorption and desorption, oxidation and reduction, volatilization, and chemical and biological transformations of selenate, selenite, and selenomethionine. In addition to simulating water flow, selenate, selenite, and selenomethionine transport, the model also simulates organic and gaseous selenium transport. The developed model was applied to simulate two different observed field data. The simulation of the observed data was satisfactory, with mean absolute error of $48.5 \mu \mathrm{g} / \mathrm{l}$ and mean relative error of $8.9 \%$.
\end{abstract}

G. Tayfur · A. Baba $(\varangle)$

Department of Civil Eng.,

İzmir Institute of Technology,

Urla, İzmir, Turkey

e-mail: alperbaba@iyte.edu.tr, alperbaba@comu.edu.tr

G. Tayfur

e-mail: gokmentayfur@iyte.edu.tr

\section{K. K. Tanji}

Department of Land, Air and Water Resources,

University of California, Davis, CA, USA

e-mail: kktanji@ucdavis.edu
Keywords Finite elements method •

Unsaturated zone $\cdot$ Selenium $(\mathrm{Se}) \cdot$ Selenate $\cdot$

Selenite $\cdot$ Selenomethionine $\cdot$ Organic Se .

Gaseous Se $\cdot$ Modeling

\section{Introduction}

Selenium (Se) belongs to a group of micronutrient elements required in very small amounts by animals and humans for the basic functions of life. Toxicity and essentiality of selenium have been widely discussed by many authors (Sager 1994a, b; Peters et al. 1997; Zhang et al. 2003; Bujdos et al. 2005; May et al. 2008). The concentration of selenium in plants and animals is strongly correlated with its concentration in soils. Plants and their derivatives transfer selenium from soils to humans (Girling 1984).

Selenium (Se) is considered to be one of the most abundant but toxic elements in the earth's crust. The large quantity of Se in the earth's crust is reported to be about $0.05-0.09 \mathrm{mg} / \mathrm{kg}$ (Alloway 1995). Se is a chalcophile element (Goldschmit 1954), and as such is associated with sulfide. As a natural constituent of soil minerals, selenium is normally present in soil at low concentrations ranging from 0.01 to $2 \mathrm{mg} / \mathrm{kg}$ (Dungan and Frankenberger 1999). The Se content of soils generally reflects the weathering of parent materials, although in certain conditions, atmospheric and 
more recently anthropogenic inputs may influence their composition. In the natural environment, elevated concentrations of Se in soils are associated primarily with volcanic materials, sulfide ore bodies, black shales, and carbonaceous sandstones (Alloway 1995). Se is most likely to be present in soils in selenate $\left(\mathrm{SeO}_{4}^{2-}\right)$ form. In humid regions, selenite $\left(\mathrm{SeO}_{3}^{2-}\right)$ appears to be the predominant specie (Adriano 1986). The use of Se as an agrochemical encompasses a variety of areas including its use in pest control and as a dietary supplement for livestock grazed in a Se-deficient area (NASNRC 1976). Under the agricultural practice of intense irrigation, Se in these soils can be leached out and further concentrated at locations where drainage water is disposed (Tanji et al. 1986, 1992; Fujii et al. 1988). Since Se contamination in soil and water causes serious damage to wildlife, significant research has been directed at the study of Se fate and its behavior in soil water systems (Frankenberger and Benson 1994; Frankenberger and Engberg 1998).

A number of laboratory and field Se transport studies were carried out to investigate Se transformations and transport (Ahlrichs and Hossner 1987; Alemi et al. 1988; Deveral and Fujii 1988; Deveral and Milliard 1988; Fujii et al. 1988; Sposito et al. 1988; Fio and Fujii 1990; Mirbagheri et al. 2008). In these studies, researchers examined the transport of several species of Se (selenate, selenite, selenomethionine) under a number of different conditions. These conditions ranged from simply steady-state feed of Se in soil columns to the transient transport of Se in the subsurface flow.

Mathematical modeling and simulation of Se transformations and transport were also attempted by several researchers (Deveral and Fujii 1988; Fio et al. 1990; Alemi et al. 1991). In these models, Se transport was mostly treated in one dimension under steady-state conditions. However, there is a need for a more comprehensive model which can treat Se transport in two dimensions under transient conditions and consider all the possible transformations of Se species. For this purpose, in this study, a validated 2-D finite element model (FEM) for water and salts transport in a saturated-unsaturated zone (Nour el-Din et al. 1987; Karajeh et al. 1994) was extended to consider Se transformations and transport.

The objective of this study is to model selenium transformations and transport in two dimensions by FEM. The model is tested with field data.

\section{Mathematical development}

Flow transport

The equation which models the transient flow in saturated-unsaturated zone in two dimensions is expressed as (Neuman 1973; Nour el-Din et al. 1987; Karajeh et al. 1994):

$$
\begin{aligned}
\left(\lambda S_{\mathrm{s}}+\frac{\partial \theta}{\partial p}\right) \frac{\partial p}{\partial t}= & \frac{\partial}{\partial x}\left[K_{\mathrm{r}} \frac{k_{x x}}{\mu} \frac{\partial p}{\partial x}\right]+\frac{\partial}{\partial z} \\
& \times\left[K_{\mathrm{r}} \frac{k_{z z}}{\mu}\left(\frac{\partial p}{\partial z}-\rho g\right)\right] \mp Q
\end{aligned}
$$

where $\lambda=$ a coefficient taken as unity in the case of saturated flow and zero in the case of unsaturated flow; $S_{\mathrm{s}}=$ the storage coefficient that describes the volume of water released from storage under a unit decline in hydraulic head; $\theta=$ volumetric water content; $p=$ soil water pressure; $K_{\mathrm{r}}=$ relative hydraulic conductivity $\left(0<K_{\mathrm{r}}<1\right)$; $k_{x x}=$ saturated hydraulic conductivity tensor in $x$ direction; $k_{z z}=$ saturated hydraulic conductivity tensor in $z$-direction; $\mu=$ kinematic viscosity; $\rho=$ the density of water; $g=$ the gravitational acceleration; and $Q=$ the strength of all sources and sinks in the system.

Equation 1 is nonlinear since the hydraulic conductivity and soil water content are functions of pressure. In order to solve Eq. 1, initial and boundary conditions need to be specified. Initial spatial distribution of the pressure needs to be specified as the initial condition. The boundary conditions can be either Dirichlet type or Neuman type for specified pressure or specified flux, respectively.

\section{Selenium transport}

The Se transport and transformation processes in a soil column under transient flow conditions are 
complex. Several complicating factors like pore water velocity gradient, hydraulic conductivity, evaporation and transpiration fluxes, concentration gradient, and seasonal rise and fall of the water table control the transport of different Se species. In general, Se is transported in soil by convection and dispersion which are the result of mass flow and concentration gradient. The Se transformation processes in soil systems are oxidation and reduction, adsorption and desorption, plant uptake, mineralization and immobilization, and volatilization.

Selenate is the most oxidized chemical species of Se with a chemical valence of $6+\left(\mathrm{Se}^{6+}\right)$. Selenate can be both chemically and biologically reduced into selenite $\left(\mathrm{Se}^{4+}\right)$, which is then further reduced to elemental $\left(\mathrm{Se}^{0}\right)$ or organic $\mathrm{Se}\left(\mathrm{Se}^{2-}\right)$. Methylation of Se is generally considered to occur on reduced Se species with a chemical valence of $\leq 4+$; however, the exact order in which the reaction steps occur is still debated (Dungan and Frankenberger 1999). These simultaneous and sequential Se reactions can be represented by the conceptual model presented in Fig. 1.

The rate of transformation of Se from selenite to selenate and vice versa through oxidation/reduction processes is very slow, but oxidation of elemental Se to selenite is somewhat more pronounced (Cary and Allaway 1969). The rate of oxidation/reduction of different species depends on factors such as the $\mathrm{Eh}, \mathrm{pH}$, and oxygen status of soil, soil temperature, microbial activity, and soil water content. In general, in alkaline soils of semiarid areas, Se exists in the selenate form. However, under acidic and reducing conditions, as in humid regions, Se may exist dominantly in the selenite form.

The process of selenate and selenite adsorption and desorption plays a crucial role in governing soil Se mobility in most acidic soils. This, in turn, affects the other Se processes in the soil, especially Se availability for plant uptake and volatilization. Since selenious acid is weaker than selenic acid, selenite is retained more strongly by soils than selenate (Balistrieri and Chao 1987; Neal and Sposito 1989; Fio and Fujii 1990; Shifang 1991). Factors affecting the processes of adsorption and desorption are the properties of adsorbents, the solution $\mathrm{pH}$, competitive anions such as $\mathrm{PO}_{4}^{3-}$, and the concentration of soil amendment $\left(\mathrm{CaCO}_{3}\right.$ and $\mathrm{CaSO}_{4}$; Hamdy and Gissel-Nielson 1977; Neal et al. 1987). The properties of adsorbents affect Se adsorption and desorption because of specific affinity sites and total surface area. Selenite adsorption was found to be positively correlated with specific areas and organic carbon. $\mathrm{pH}$ is very sensitive factor with respect to Se adsorption since it affects both surface electrochemical potential and Se redox potential (Hamdy and GisselNielson 1977).

Se volatilization from soils has often been reported as being a result of microbial processes. The conversion of added Se to volatile gases was enhanced when soils were amended with organic matter (Karlson and Frankenberger 1989; Thompson-Eagle and Frankenberger 1990). Factors affecting the volatilization of soil Se are soil $\mathrm{pH}$, soil temperature, organic matter content, liming and moisture content, microbial activity, and plant growth (Gissler-Nielson 1973, 1976; Hamdy and Gissel-Nielson 1977; Mushak 1985; Thompson-Eagle and Frankenberger 1990; Biggar and Jayaweera 1990). Gissler-Nielson (1976) from their studies concluded that the change in soil moisture content and the increase in liming, organic matter content, temperature, carbon sources, and protein sources increase the volatilization.

Se is absorbed by plants in both the inorganic form, such as selenate and selenite, and the organic form, as selenomethionine (Johnson et al. 1967; Gissler-Nielson 1973; Statman 1974). The factors affecting the Se uptake by plants are: soil moisture content, plant type, soil $\mathrm{pH}$, soil texture, soil solution salinity, organic matter content, competitive anions such as $\mathrm{SO}_{4}^{2-}$ and $\mathrm{PO}_{4}^{3-}$, tillage, and fertilizer (Carter et al. 1972; Westernman and Robbins 1974; Gissler-Nielson 1973, 1976; Hamdy and Gissel-Nielson 1977). In soils with a high content of organic matter and iron oxides, the selenite is very strongly fixed and thereby unavailable to plants (Gissler-Nielson 1973, 1976; Hamdy and Gissel-Nielson 1977). Sandy soil retains less Se than clay soil but is more available for plant uptake. Low $\mathrm{pH}$ favors the fixation of selenite to the clay minerals, while high $\mathrm{pH}$ favors the 

selenium in soil $\left[\mu_{i}\right.$, is the forward or backward reaction rate coefficients among various Se species]
Fig. 1 Reactions of

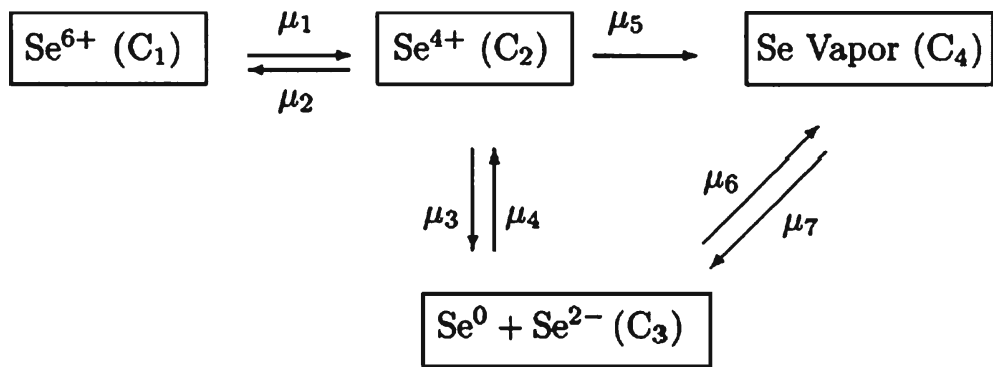

oxidation of selenite to the far more easily extractable selenates. Carter et al. (1972) suggested that plant uptake of selenite might be increased by phosphate $\left(\mathrm{PO}_{4}^{3-}\right)$, probably because of adsorbed selenite displacement, increased root growth, and enhanced microbial activities. Se concentration in plants decreases with the addition of $\mathrm{SO}_{4}^{2-}$ because of $\mathrm{Se}_{-} \mathrm{SO}_{4}^{2-}$ antagonism effects. Soil solution salinity decreases Se uptake, while tillage and fertilizer increases Se uptake due to soil aeration and stimulation of microbial activities and root growth (Westernman and Robbins 1974).

In the following section, the equations expressing selenate, selenite, and selenomethionine transport in two dimensions are given. Each equation comprises the advection diffusion terms and all the possible sink and source terms resulting from transformations and plant uptake.

Selenate transport

$$
\begin{aligned}
\frac{\partial}{\partial t}\left(R_{1} C_{1}\right) \\
=\frac{\partial}{\partial x}\left[\theta D_{1 x} \frac{\partial C_{1}}{\partial x}\right]+\frac{\partial}{\partial z}\left[\theta D_{1 z} \frac{\partial C_{1}}{\partial z}\right] \\
-\frac{\partial}{\partial x}\left(C_{1} q_{x}\right)-\frac{\partial}{\partial z}\left(C_{1} q_{z}\right)-\left(\lambda_{\mathrm{a} 1} \alpha_{1} U C_{1}\right) \\
\quad-\left[\left(K_{\mathrm{r} 1}+K_{\mathrm{v} 1}+K_{\mathrm{b} 1}\right) \theta C_{1}\right]+\left(\rho_{\mathrm{s}} K_{\mathrm{m} 1} S_{\mathrm{o}}\right)
\end{aligned}
$$

where

$$
R_{1}=\left[\theta+\rho_{\mathrm{s}}\left(K_{\mathrm{a} 1} n C_{1}^{n-1}\right)\right]
$$

where $C_{1}=$ selenate concentration $(\mathrm{mg} / \mathrm{l}) ; R_{1}=$ retardation factor for selenate; $\rho_{\mathrm{s}}=$ bulk density of the porous medium $\left(\mathrm{kg} / \mathrm{m}^{3}\right) ; K_{\mathrm{a} 1}=$ adsorption coefficient for selenate $(1 / \mathrm{kg}) ; n=$ nonequilibrium exponent for selenate; $D_{1 x}=$ total diffusion coefficient for selenate in $x$-direction $\left(\mathrm{cm}^{2} /\right.$ day);
$D_{1 z}=$ total diffusion coefficient for selenate in $z-$ direction $\left(\mathrm{cm}^{2} /\right.$ day $) ; \theta=$ volumetric water content; $q_{x}=$ Darcy flux in $x$-direction $\left(q_{x}=\theta v_{x}\right.$, where $v_{x}=$ pore water velocity in $x$-direction; $\mathrm{cm} /$ day); $q_{z}=$ Darcy flux in $z$-direction $\left(q_{z}=\theta v_{z}\right.$, where $v_{z}=$ pore water velocity in $z$-direction; $\mathrm{cm} /$ day); $\lambda_{\mathrm{a} 1}=$ root absorption coefficient for selenate; $\alpha_{1}=$ coefficient for $\mathrm{SO}_{4}^{2-}$ antagonism effect for selenate; $U=$ root water extraction $(1 /$ day $) ; K_{\mathrm{r} 1}=$ transformation rate constant for reduction of selenate $(1 /$ day $) ; K_{\mathrm{v} 1}=$ volatilization rate constant of selenate $(1 /$ day $) ; K_{\mathrm{b} 1}=$ transformation rate constant for immobilization of selenate (1/day); $K_{\mathrm{m} 1}=$ transformation rate constant for mineralization of selenate (1/day); and $S_{\mathrm{o}}=$ organic selenium concentration $(\mathrm{mg} / \mathrm{kg})$.

Selenite transport

$$
\begin{aligned}
\frac{\partial}{\partial t}( & \left.R_{2} C_{2}\right) \\
= & \frac{\partial}{\partial x}\left[\theta D_{2 x} \frac{\partial C_{1}}{\partial x}\right]+\frac{\partial}{\partial z}\left[\theta D_{2 z} \frac{\partial C_{1}}{\partial z}\right] \\
& -\frac{\partial}{\partial x}\left(C_{2} q_{x}\right)-\frac{\partial}{\partial z}\left(C_{2} q_{z}\right)-\left(\lambda_{\mathrm{a} 2} \alpha_{2} U C_{2}\right) \\
& -\left[\left(K_{\mathrm{r} 2}+K_{\mathrm{v} 2}+K_{\mathrm{b} 2}\right) \theta C_{2}\right]+\left(\rho_{s} K_{m 2} S_{\mathrm{o}}\right) \\
& +\left(K_{r 1} \theta C_{1}\right)
\end{aligned}
$$

where

$R_{2}=\left[\theta+\rho_{\mathrm{s}}\left(K_{\mathrm{a} 2} w C_{2}^{w-1}\right)\right]$

where $C_{2}=$ selenite concentration $(\mathrm{mg} / \mathrm{l}) ; R_{2}=$ retardation factor for selenite; $K_{\mathrm{a} 2}=$ adsorption coefficient for selenite $(1 / \mathrm{kg}) ; w=$ nonequilibrium exponent for selenite; $D_{2 x}=$ total diffusion coefficient for selenite in $x$-direction $\left(\mathrm{cm}^{2} /\right.$ day); $D_{2 z}=$ total diffusion coefficient for selenite in 
$z$-direction $\left(\mathrm{cm}^{2} /\right.$ day $) ; \lambda_{\mathrm{a} 2}=$ root absorption coefficient for selenite; $\alpha_{2}=$ coefficient for $\mathrm{SO}_{4}^{2-}$ antagonism effect for selenite; $K_{\mathrm{r} 2}=$ transformation rate constant for reduction of selenite $(1 /$ day $) ; K_{\mathrm{v} 2}=$ volatilization rate constant of selenite (1/day); $K_{\mathrm{b} 2}=$ transformation rate constant for immobilization of selenite (1/day); and $K_{\mathrm{m} 2}=$ transformation rate constant for mineralization of selenite (1/day).

Selenomethionine transport

$$
\begin{aligned}
\frac{\partial}{\partial t}( & \left.R_{3} C_{3}\right) \\
= & \frac{\partial}{\partial x}\left[\theta D_{3 x} \frac{\partial C_{3}}{\partial x}\right]+\frac{\partial}{\partial z}\left[\theta D_{3 z} \frac{\partial C_{3}}{\partial z}\right] \\
& -\frac{\partial}{\partial x}\left(C_{3} q_{x}\right)-\frac{\partial}{\partial z}\left(C_{3} q_{z}\right)-\left(\lambda_{\mathrm{a} 3} \alpha_{3} U C_{3}\right) \\
& -\left(K_{\mathrm{v} 3} \theta C_{3}\right)+\left(\rho_{\mathrm{s}} K_{\mathrm{m} 3} S_{\mathrm{o}}\right)
\end{aligned}
$$

where

$$
R_{3}=\left[\theta+\rho_{s}\left(K_{\mathrm{a} 3} l C_{3}^{l-1}\right)\right]
$$

where $C_{3}=$ selenomethionine concentration $(\mathrm{mg} / \mathrm{l})$; $R_{3}=$ retardation factor for selenomethionine; $K_{\mathrm{a} 3}=$ adsorption coefficient for selenomethionine $(1 / \mathrm{kg}) ; l=$ nonequilibrium exponent for selenomethionine; $D_{3 x}=$ total diffusion coefficient for selenomethionine in $x$-direction $\left(\mathrm{cm}^{2} /\right.$ day $) ; D_{3 z}=$ total diffusion coefficient for selenomethionine in $z$-direction $\left(\mathrm{cm}^{2} /\right.$ day $) ; \lambda_{\mathrm{a} 3}=$ root absorption coefficient for selenomethionine; $\alpha_{3}=$ coefficient for $\mathrm{SO}_{4}^{2-}$ antagonism effect for selenomethionine; $K_{\mathrm{v} 3}=$ volatilization rate constant of selenomethionine (1/day); and $K_{\mathrm{m} 3}=$ transformation rate constant for mineralization of selenomethionine (1/day).

The rate of change in organic selenium can be expressed as:

$$
\begin{aligned}
\frac{\partial S_{\mathrm{o}}}{\partial t}= & \frac{\theta}{\rho_{\mathrm{s}}} K_{\mathrm{b} 1} C_{1}+\frac{\theta}{\rho_{\mathrm{s}}} K_{\mathrm{b} 2} C_{2}-K_{\mathrm{m} 1} S_{\mathrm{o}} \\
& -K_{\mathrm{m} 2} S_{\mathrm{o}}-K_{\mathrm{m} 3} S_{\mathrm{o}}
\end{aligned}
$$

The rate of change in gaseous selenium can be expressed as:

$$
\frac{\partial G}{\partial t}=\frac{\theta}{\rho_{\mathrm{s}}} K_{\mathrm{v} 1} C_{1}+\frac{\theta}{\rho_{\mathrm{s}}} K_{\mathrm{v} 2} C_{2}+\frac{\theta}{\rho_{\mathrm{s}}} K_{\mathrm{v} 3} C_{3}
$$

where $G$ is gaseous selenium concentration $(\mu \mathrm{g} / \mathrm{kg})$. Numerical solution of the transport equations requires initial and boundary conditions. As an initial condition, zero concentrations along the soil profile are specified. The boundary conditions can be specified as Dirichlet type, Neuman type, and Cauchy type for specified concentration, zero flux, and prescribed flux, respectively. The details can be obtained from Nour el-Din et al. (1987) and Karajeh et al. (1994) where the flow part of the model was already tested and validated.

\section{Model application to field data}

The extended model was applied to simulate two different data sets obtained from the Mendota site, CA, USA. In the USA, various anthropogenic activities have greatly increased the mobilization and transport of selenium into aquatic ecosystems. From the 1960s through the 1980s, selenium mobilization on a regional and national scale largely was a result of two causes: (1) procurement, processing, and combustion of fossil fuels and (2) irrigation of seleniferous soils for crop production in arid and semiarid regions (Lemly et al. 1993; May et al. 2001).

A critical agricultural and environmental problem emerged in California's San Joaquin Valley in the 1980s when saline subsurface drainage waters from 17,000 ha of waterlogged croplands were impounded in the Kesterson Reservoir. Cooke and Bruland (1987) identified various soluble Se species in surface waters at Kesterson Reservoir and San Joaquin River. Discharge of drainage water with high Se concentration was identified as the primary source of Se in the Kesterson National Wildlife Refuge (Deverel et al. 1984). The evapoconcentration of drain waters containing about $300 \mu \mathrm{g} / \mathrm{l}$ of selenium (Se) and its subsequent biomagnification and bioaccumulation in the aquatic food chain resulted in the reduced reproduction, deformity, and death of waterbirds (NRC 1989).

The 1984 discovery of Se toxicosis in birds at the Kesterson National Wildlife Refuge triggered a massive federal/state investigation known as the San Joaquin Valley Drainage Program (SJVDP). Upon completion of a 6-year investigation, the SJVDP (1990) recommended a broad array of management options to solve the drainage related 
Table 1 Soil characteristics parameters for soil type I (silty clay) and soil type II (clay)

\begin{tabular}{llllllll}
\hline Soil type & $\theta_{\mathrm{r}}$ & $\theta_{\mathrm{s}}$ & $\alpha$ & $n$ & $\mathrm{Se}$ & $K_{\mathrm{s}}(\mathrm{cm} / \mathrm{day})$ & $\rho_{\mathrm{b}}(\mathrm{gr} / \mathrm{cm} 3)$ \\
\hline I & 0.02530 & 0.425 & 0.0250 & 1.65 & 0.0002 & 13.3 & 1.385 \\
II & 0.02525 & 0.425 & 0.0129 & 1.98 & 0.0002 & 13.3 & 1.385 \\
\hline
\end{tabular}

$\theta_{\mathrm{s}}$ and $\theta_{\mathrm{r}}$ are the saturated and residual field volumetric water contents, respectively; $K_{\mathrm{s}}$ is the saturated hydraulic conductivity; $n$ and $\alpha$ are statistical parameters to be found by the least-square fitting for the specific soil type using the model of van Genuchten, and $\mathrm{S}_{\mathrm{e}}$ is the reduced water content (see Nour el-Din et al. (1987) and Karajeh et al. (1994))

problems in the 0.9 million hectares of croplands of which $39 \%$ are waterlogged. One management option recommended was the reuse of drain waters in agroforestry systems comprised of salttolerant trees and shrubs. Drain water reuse was one of the few viable options available in those areas of irrigated croplands where there was little or no opportunity for discharge of irrigation return flows. This particular management option reduced the volume of unusable waters and concentrated salinity and trace elements for easier disposal and/or treatment. Moreover, reuse of drain water in agroforestry systems was also a remedial measure in itself because a portion of the salts and selenium participated in sink mechanisms.

The California Department of Food and Agriculture (CDFA) and USDA's Soil Conservation Service initiated trial tree plantings in the valley to lower the shallow groundwater and use saline drain waters as irrigation of trees such as Eucalyptus and Atriplex (Cervinka 1987). By 1990 , over 0.5 million trees had been planted on 226 ha in 41 farms. Most of this effort was directed toward selection of salt-tolerant eucalyptus trees and their growth performance in saline soil environments. One of these farms was located in Mendota, CA, USA. Saline drain waters from nearby croplands, having an average electrical conductivity (EC) of $10 \mathrm{dS} / \mathrm{m}$ and Se concentration of $400 \mu \mathrm{g} / \mathrm{l}$, were being used to irrigate the Eucalyptus camaldulensis. Tile effluents from this tree plantation had an average EC of $32 \mathrm{dS} / \mathrm{m}$ and Se concentration of $700 \mu \mathrm{g} / \mathrm{l}$. The tile effluents were then collected in evaporation tanks for salt harvest. From 1987 to 1990, there was a substantial buildup of soil salinity and Se. There was a need to assess the environmental fate pathways of $\mathrm{Se}$ in tree plantations utilizing saline drain waters containing elevated concentrations of Se.

The first data set belongs to the 1985-1990 plantations, and the second one belongs to the 1992 plantations. The Mendota site is the first monitored agroforestry demonstration project established by the Natural Resources Conservation Service and CDFA. The experimental site consists of fine-textured silty clay $(0$ to $60 \mathrm{~cm})$ to clay soils $(60$ to $300 \mathrm{~cm}$ ) underlain by an impermeable clay layer at 3- to 3.7-m depths over the entire plantation. Table 1 shows the soil property parameters for the two soil layers. Several lines of $E$. camaldulensis were planted in 1985 and 1986. The underdrainage system was installed in 1987. The
Fig. 2 Finite-element mesh with 616 elements and 669 nodes

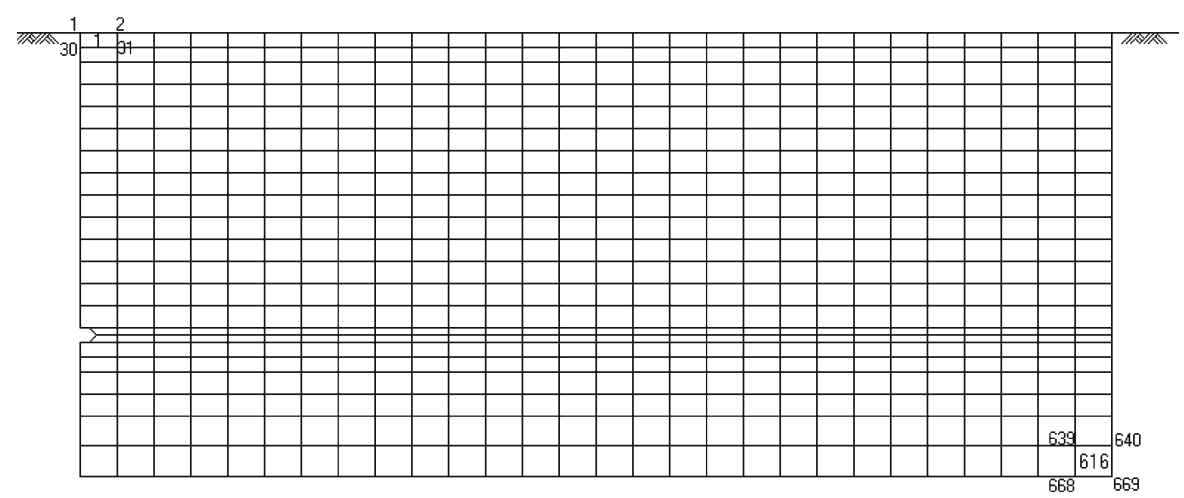


trees were surface-irrigated with saline drainage waters collected from croplands about 2 years after planting. The irrigation was performed from April to November of each year. The total irrigation depths were $370 \mathrm{~mm}$ in 1988, $530 \mathrm{~mm}$ in 1989, and $1,055 \mathrm{~mm}$ in 1990. The irrigation rates were applied almost every 10 days for about $24 \mathrm{~h}$. The irrigation application efficiency, which shows the amount of water stored in the crop root zone compared to the amount of irrigation water applied, was $75 \%$. The average annual crop evapotranspiration depth was about $450 \mathrm{~mm}$. The average Se concentration in the irrigation water was $400 \mu \mathrm{g} / \mathrm{l}$. The trees performed remarkably well until they suffered killing frost damage in December 1990. Most of the detailed observations were made between the fall of 1987 and the summer of 1990. For model simulation, a finite element mesh with 616 elements and 669 nodes was constructed (Fig. 2). In order to capture the effect of gradients in the solution domain, the number of elements was increased; thereby, the size of elements was kept smaller. The model coefficients of the sink and source terms in the main equations were compiled from Hutson and Wagenet (1989), Fio et al. (1990), Thompson-Eagle and Frankenberger (1990), Biggar and Jayaweera (1990), Alemi et al. (1991), and Shifang (1991). Table 2 shows model predictions of measured data at the Mendota site in 1990. Since there were only four observations along the soil depth, we presented the results in a tabulated format. As seen in Table 2, the model closely predicted measured data. Following the killing frost of 1990 at the Mendota site and subsequent harvest of the trees, several lines of frost-tolerant Eucalyptus trees were planted in 1992. The experimental site was redesigned and automated for water flows, and the soils were also leached. Table 3 shows the model predictions of the measured Se concentration data in 1992. As can be seen, the model closely captured the

Table 2 FEM model predictions of Se concentrations at Mendota site (1990 observations)

\begin{tabular}{lclll}
\hline Soil depth $(\mathrm{cm})$ & 53 & 110 & 158 & 210 \\
Observed Se data $(\mu \mathrm{g} / \mathrm{l})$ & 500 & 550 & 600 & 800 \\
Model predictions $(\mu \mathrm{g} / \mathrm{l})$ & 543.2 & 550.6 & 552 & 557.4 \\
\hline
\end{tabular}

Table 3 FEM model predictions of Se concentrations at Mendota Site (1992 observations)

\begin{tabular}{lllll}
\hline Soil depth $(\mathrm{cm})$ & 53 & 110 & 158 & 210 \\
Observed Se data $(\mu \mathrm{g} / \mathrm{l})$ & 59 & 258 & 270 & 326 \\
Model predictions $(\mu \mathrm{g} / \mathrm{l})$ & 63.4 & 267.9 & 284.5 & 301.2 \\
\hline
\end{tabular}

measured data. The computed error measures for the results in Tables 2 and 3 are mean absolute error $=48.5 \mu \mathrm{g} / \mathrm{l}$ and mean relative error $=8.9 \%$. These results imply that the model can produce a less than $10 \%$ error in predicting measured $\mathrm{Se}$ concentration in the soil zone. However, it should be noted the model cannot handle the rapid concentration variations at critical depths which are located at the tile drainage.

\section{Concluding remarks}

In this study, the two-dimensional FEM was extended to simulate Se transport in a saturatedunsaturated crop root zone. The model can simulate seasonal variations of soil water content and Se concentration distribution in irrigated and underdrained agroforestry systems. The model considers water, selenate, selenite, and selenomethionine uptake by plats, adsorption and desorption, oxidation and reduction, volatilization, and chemical and biological transformations of selenate, selenite, and selenomethionine. In addition to simulating water flow, selenate, selenite, and selenomethionine transport, the model also simulates organic and gaseous selenium transport.

The successful predictions of measured filed data sets indicate that the developed model can be employed for the management of selenium transport in agroforestry sites. It is, however, worth noting that the model cannot handle the rapid concentration variations at critical depths (which are located at the tile drainage). When applied to field situations, this shortcoming of the model should be taken into account.

It also needs to be pointed out that the extended model requires extensive field data such as relative and saturated hydraulic conductivities, relative and saturated soil moisture, porosity, bulk density, diffusion coefficients, and parameters and constants for the volatilization, immobilization, 
transformation, and mineralization processes for different soils in both horizontal and vertical directions. In addition, it requires the estimation of van Genuchten infiltration parameters and hydrometeorological data for the computation of evapotranspiration. Furthermore, it requires parameter values such as the absorption coefficient and root effectiveness function for different trees. As such, for realistic field applications, the model needs to be provided with the required data on soil, flow, and tree properties. It is, however, well known that it is not usually possible to obtain all the data due to time and budgetary constraints. Instead, representative samples at different locations and different depths can be obtained from the field and subjected to laboratory analysis to provide some of the parameter values. Some parameter values can be complied from the literature, and some can be estimated through statistical methods.

\section{Notation}

$C_{1} \quad$ Selenate concentration $(\mathrm{mg} / \mathrm{l})$

$C_{2} \quad$ Selenite concentration $(\mathrm{mg} / \mathrm{l})$

$C_{3} \quad$ Selenomethionine concentration $(\mathrm{mg} / \mathrm{l})$

$D_{1 x} \quad$ Total diffusion coefficient for selenate in $x$-direction $\left(\mathrm{cm}^{2} /\right.$ day $)$

$D_{1 z} \quad$ Total diffusion coefficient for selenate in $z$-direction $\left(\mathrm{cm}^{2} /\right.$ day $)$

$D_{2 x} \quad$ Total diffusion coefficient for selenite in $x$-direction $\left(\mathrm{cm}^{2} /\right.$ day $)$

$D_{2 z} \quad$ Total diffusion coefficient for selenite in $z$-direction $\left(\mathrm{cm}^{2} /\right.$ day $)$

$D_{3 x}$ Total diffusion coefficient for selenomethionine in $x$-direction $\left(\mathrm{cm}^{2} /\right.$ day)

$D_{3 z}$ Total diffusion coefficient for selenomethionine in $z$-direction $\left(\mathrm{cm}^{2} /\right.$ day $)$

$g \quad$ Gravitational acceleration

$G \quad$ Gaseous selenium concentration $(\mu \mathrm{g} / \mathrm{kg})$

$K_{\mathrm{a} 1} \quad$ Adsorption coefficient for selenate $(\mathrm{l} / \mathrm{kg})$

$K_{\mathrm{a} 2} \quad$ Adsorption coefficient for selenite ( $\left.1 / \mathrm{kg}\right)$

$K_{\mathrm{a} 3}$ Adsorption coefficient for selenomethionine $(1 / \mathrm{kg})$

$K_{\mathrm{b} 1}$ Transformation rate constant for immobilization of selenate (1/day)

$K_{\text {b2 }}$ Transformation rate constant for immobilization of selenite (1/day)
$K_{\mathrm{m} 1}$ Transformation rate constant for mineralization of selenate (1/day)

$K_{\mathrm{m} 2}$ Transformation rate constant for mineralization of selenite (1/day)

$K_{\mathrm{m} 3}$ Transformation rate constant for mineralization of selenomethionine (1/day)

$K_{\mathrm{r}} \quad$ Relative hydraulic conductivity $(0<$ $\left.K_{\mathrm{r}}<1\right)$

$K_{\mathrm{r} 1}$ Transformation rate constant for reduction of selenate (1/day)

$K_{\mathrm{r} 2}$ Transformation rate constant for reduction of selenite (1/day)

$K_{\mathrm{v} 1} \quad$ Volatilization rate constant of selenate (1/day)

$K_{\mathrm{v} 2}$ Volatilization rate constant of selenite (1/day)

$K_{\mathrm{v} 3}$ Volatilization rate constant of selenomethionine (1/day)

$k_{x x}$ Hydraulic conductivity tensor in $x$ direction

$k_{z z} \quad$ Saturated hydraulic conductivity tensor in $z$-direction

$l \quad$ Nonequilibrium exponent for selenomethionine

$n \quad$ Nonequilibrium exponent for selenate

$p \quad$ Soil water pressure

$Q \quad$ Strength of all sources and sinks in the system

$q_{x} \quad$ Darcy flux in $x$-direction

$q_{z} \quad$ Darcy flux in $z$-direction

$R_{1} \quad$ Retardation factor for selenate

$R_{2} \quad$ Retardation factor for selenite

$R_{3} \quad$ Retardation factor for selenomethionine

$S_{\mathrm{o}} \quad$ Organic selenium concentration $(\mathrm{mg} / \mathrm{kg})$

$S_{\mathrm{s}} \quad$ Storage coefficient that describes the volume of water released from storage under a unit decline in hydraulic head

$U \quad$ Root water extraction (1/day)

$w \quad$ Nonequilibrium exponent for selenite

$\alpha_{1} \quad$ Coefficient for $\mathrm{SO}_{4}^{2-}$ antagonism effect for selenate

$\alpha_{2} \quad$ Coefficient for $\mathrm{SO}_{4}^{2-}$ antagonism effect for selenite

$\alpha_{3} \quad$ Coefficient for $\mathrm{SO}_{4}^{2-}$ antagonism effect for selenomethionine

$\mu \quad$ Kinematic viscosity

$\lambda$ Coefficient taken as unity in the case of saturated flow and zero in the case of unsaturated flow 
$\lambda_{\mathrm{a} 1} \quad$ Root absorption coefficient for selenate

$\lambda_{\mathrm{a} 2} \quad$ Root absorption coefficient for selenite

$\lambda_{\mathrm{a} 3}$ Root absorption coefficient for selenomethionine

$\theta \quad$ Volumetric water content

$\rho \quad$ Density of water

$\rho_{\mathrm{s}} \quad$ Bulk density of the porous medium $\left(\mathrm{kg} / \mathrm{m}^{3}\right)$

Acknowledgements We thank Emin Yurekliturk for creating the figures and the financial support provided for him by the Izmir Institute of Technology, 2001MUHYL12.

\section{References}

Adriano, D. C. (1986). Trace element in terrestrial environment (Chapter 12). New York: Springer.

Ahlrichs, J. S., \& Hossner, L. R. (1987). Selenate and selenite mobility in overburden by saturated flow. Journal of Environmental Quality, 16, 95-98.

Alemi, M. H., Goldhamer, D. A., \& Nielson, D. R. (1988). Selenate transport in steady-state water saturated soil columns. Journal of Environmental Quality, 17, 608-613.

Alemi, M. H., Goldhamer, D. A., \& Nielson, D. R. (1991). Modeling selenium transport in steady-state, unsaturated soil columns. Journal of Environmental Quality, 20, 89-95.

Alloway, B. J. (1995). Heavy metals in soils (2nd ed.). Glasgow: Blackie Academic.

Balistrieri, L. S., \& Chao, T. T. (1987). Selenium adsorption by goethite. Soil Science Society of America Journal, $51,1145-1151$.

Biggar, J. W., \& Jayaweera (1990). Soil-water vegetation management studies of selenium in Kesterson Restoration and Contaminant Project, December 1990.

Bujdos, M., Mulova, A., Kubova, J., \& Medved, J. (2005). Selenium fractionation and speciation in rocks, soils, waters and plants in polluted surface mine environment. Environmental Geology, 47, 353-360.

Carter, D. L., Robbins, C. W., \& Brown, M. J. (1972). Effect of phosphorous fertilization on the selenium concentration in alfalfa (Medicago sativa). Soil Science Society American Proceedings, 36, 624-628.

Cary, E. E., \& Allaway, W. H. (1969). The solubility of different forms of selenium applied to low selenium soils. Soil Science Society of America Journal, 33, 571-574.

Cervinka, V. (1987). Agroforestry systems for the management of drain water in the San Joaquin Valley of California. Presented at the ASAE Pacific Region Meeting, Tucson, AZ, p. 6.

Cooke, T. D., \& Bruland, K. W. (1987). Aquatic chemistry of selenium: Evidence of biomethylation. Environmental Science (Technical), 21, 1214-1219.

Deveral, S. J., \& Fujii, R. (1988). Processes affecting the distribution of selenium in shallow ground wa- ter of agricultural areas, Western San Joaquin Valley, California. Water Resources Research, 24, 516-524.

Deverel, S. J., Gilliom, R. J., Fujii, R., Izbickii, J. A., \& Fields, J. C. (1984). A real distribution of selenium and other inorganic constituents in shallow ground water of the San Luis Drain Service Area, San Joaquin Valley, California: A preliminary study. In Water Research Investigation Report 84, 4319 (p. 67). Reston: US Geological Survey.

Deveral, S. J., \& Milliard, S. P. (1988). Distribution and mobility of selenium and their trace elements in shallow ground water of Western San Joaquin Valley. Environmental Science \& Technology, 22, 697-702.

Dungan, R. S., \& Frankenberger, Jr., W. T. (1999). Microbial transformations of selenium and the bioremediation of seleniferous environments. Bioremediation Journal, 3, 171-188.

Fio, J. L., \& Fujii, R. (1990). Selenium speciation methods and application to soil saturation extracts from San Joaquin Valley, California. Soil Science Society of America Journal, 54, 363-369.

Fio, J. L., Fujii, R., \& Deveral, S. J. (1990). Evaluation of selenium mobility in soil using sorption experiments and a numerical model, Western San Joaquin Valley, California. USGS Open File Report 90-135, p. 38. Sacramento, CA.

Frankenberger, W. T., \& Benson, S. (1994). Selenium in environment. New York: Marcel Dekker.

Frankenberger, W. T., \& Engberg, R. A. (1998). Environmental chemistry of selenium. New York: Marcel Dekker.

Fujii, R., Deveral, S. J., \& Hayfield, D. B. (1988). Distribution of selenium in soils of agricultural fields, Western San Joaquin Valley, California. Soil Science Society of America Journal, 52, 1274-1283.

Girling, C. A. (1984). Selenium in agriculture and the environment. Agriculture, Ecosystems and Environment, $11,37-65$.

Gissler-Nielson, G. (1973). Uptake and distribution of added selenite and selenate by barley and red clover as influenced by sulfur. Journal of the Science of Food and Agriculture, 24, 749-755.

Gissler-Nielson, G. (1976). Selenium in soils and plants. In Proc. sympos. On selenium and telluvium in environment, Notre Dane, Indiana, USA.

Goldschmit, V. M. (1954). Geochemistry. NJ: Oxford University Press.

Hamdy, A. A., \& Gissel-Nielson, G. (1977). Fixation of selenium by clay minerals and iron oxides. Zeitschrift für Pflanzenernährung und Bodenkunde, 140, 63-70.

Hutson, J. L., \& Wagenet, R. J. (1989). Leaching estimation and chemistry model, a process-based model of water and solute movement, transformations, plant uptake and chemical reactions in the unsaturated zone (p. 148). Ithaca: Cornell University.

Johnson, C. M., Asher, C. J., \& Broyer, T. C. (1967). In O. J. Muth (Ed.), Selenium in biomedicine. Westport: AVI.

Karajeh, F. F., Tanji, K. K., \& King, I. P. (1994). Agroforestry drainage management model. I: Theory and 
validation. Journal of Irrigation and Drainage Engineering, ASCE, 120(2), 363-381.

Karlson, U., \& Frankenberger, W. T. (1989). Accelerated rates of selenium volatilization from California soils. Soil Science Society of America Journal, 53, 749-753.

Lemly, A. D., Finger, S. E., \& Nelson, M. K. (1993). Sources and impacts of contaminants in arid wetlands. Environmental Toxicology and Chemistry, 12, 2265.

May, T. W., Fairchild, J. F., Petty, J. D., Walther, M. J., Lucero, J., Delvaux, M., et al. (2008). An evaluation of selenium concentrations in water, sediment, invertebrates, and fish from the Solomon River Basin. Environmental Monitoring and Assessment, 137, 213-232.

May, T. W., Walther, M. J., Petty, J. D., Fairchild, J. F., Lucero, J., Delvaux, M., et al. (2001). An evaluation of selenium concentrations in water, sediment, invertebrates, and fish from the Republican River Basin: 1997-1999. Environmental Monitoring and Assessment, 72, 179-206.

Mirbagheri, S. A., Tanji, K. K., \& Rajaee, T. (2008). Selenium transport and transformation modelling in soil columns and ground water contamination prediction. Hydrological Processes, 22, 2475-2483.

Mushak, P. (1985). Potential impact of acid precipitation on arsenic and selenium. Environmental Health Perspectives, 63, 105-113.

NAS-NRC (1976). Selenium, assembly of life sciences. Washington D.C.: National Academy of Science, National Research Council.

NRC (1989). Irrigation-induced water quality problems. What can be learned from the San Joaquin Valley experience. In National Research Council (NRC) Committee on Irrigation-Induced Water Quality Problems (p. 157). Washington. D.C.: National Academy Press.

Neal, R. H., \& Sposito, G. (1989). Selenite adsorption on alluvial soils. Soil Science Society of America Journal, $53,70-74$.

Neal, R. H., Sposito, G., Holtzclaw, K. M., \& Traina, S. J. (1987). Selenite sorption on alluvial soils, II. Solution composition effects. Soil Science Society of America Journal, 51, 1165-1169.

Neuman, S. P. (1973). Saturated-unsaturated seepage by finite elements. Journal of the Hydraulics Division, ASCE, 99(12), 2233-2250.
Nour el-Din, M. M., King, I. P., \& Tanji, K. K. (1987). Salinity management model: I. Development. Journal of Irrigation and Drainage Engineering, ASCE, 113(4), 440-453.

Peters, G. M., Maher, W., Barford, J. P., \& Gomes, V. (1997). Selenium associations in estuarine sediments: Redox effects. Water, Air and Soil Pollution, 99, 275-282.

Sager, M. (1994a). Selenium, occurrence and ecology. In M. Vernet (Ed.), Environmental contamination. Amsterdam: Elsevier.

Sager, M. (1994b). Spurenanalytik des Selens, Analytiker Taschenbuch Band 12 (pp. 257-312). Berlin: Springer.

Shifang, F. (1991). Selenite adsorption/desorption in the California soils. Ph.D. Dissertation, Soil Science, Univ. of Calif. at Davis, p. 191.

SJVDP (1990). A management plan for agricultural surface drainage and related problems on the Westside San Joaquin Valley. Final report (p. 183). Sacramento, CA: San Joaquin Valley Drainage Program, USDI and CA Resources Agency.

Sposito, G., de Wit, C. M., \& Neal, R. H. (1988). Selenite adsorption on alluvial soils, III: Chemical modeling. Soil Science Society of America Journal, 52, 947-950.

Statman, T. (1974). Selenium uptake by plant. Science, 183, 915-922.

Tanji, K. K., Lauchli, A., \& Meyer, J. (1986). Selenium in the San Joaquin valley. Environment, 28, 6-39.

Tanji, K. K., Ong, C. G. H., Dahlgren, R. A., \& Herbel, M. J. (1992). Salt deposits in evaporation ponds: An environmental hazard? California Agriculture, 46, 18-21.

Thompson-Eagle, E. T., \& Frankenberger, W. T. (1990). Volatilization of selenium from agricultural evaporation pond water. Journal of Environmental Quality, 19, $125-131$.

Westernman, D. T., \& Robbins, C. W. (1974). Effects of $\mathrm{SO}_{4}^{2-}$ fertilization on $\mathrm{Se}$ concentration of alfalfa. Agronomy Journal, 66, 207-218.

Zhang, Y., Pan, G., Chen, J., \& Hu, O. (2003). Uptake and transport of selenite and selenate by soybean seedlings of two genotypes. Plant and Soil, 253, 437-443. 